\title{
EDITORIAL
}

\section{LA REVISTA CHILENA DE DERECHO Y EL INCENTIVO A LA INVESTIGACIÓN JURÍDICA}

Las revistas jurídicas reflejan, por una parte, y, a la vez, dependen de la investigación que los autores realizan en las distintas áreas de nuestra disciplina. Más aún, en una publicación de corte generalista como la nuestra, resulta indispensable poder contar con aportes de todas las especialidades del Derecho, lo que no siempre es fácil, pues según su naturaleza y aplicaciones, algunas de ellas producen más literatura y estudios que otras en el país.

Por esta causa, la Dirección de la Revista consideró la importancia de tomar un papel más activo en la producción científica en algunas especialidades del Derecho que, si bien cuentan con un fructífero ejercicio profesional y gran aplicación práctica, se muestran, sin embargo, algo reticentes a volcar ese rico aporte en artículos científicos o lo hacen más bien a través de vastos estudios que constituyen obras monográficas de gran extensión, ello con el objeto de contar con artículos y nuevas visiones sobre tales áreas publicables en nuestra Revista.

En ese contexto, y como resultado de la postulación de la Revista al concurso CONICYT 2010, de incentivo para publicación de revistas científicas, se adjudicó esta fondos para la ejecución del proyecto FP10014 "Revista Chilena de Derecho: modernización, expansión e incentivo al desarrollo del conocimiento científico-jurídico”. Entre los programas a desarrollar contenidos en dicho proyecto, se encontraba la creación de un premio que funcionase como una instancia de fomento para la publicación de trabajos asociados con el objetivo antes indicado y, de paso, se buscaba, a través de este premio, consolidar un reconocimiento de prestigio en nuestro medio académico, de la mano con las casi cuatro décadas de nuestra Revista.

En esta primera versión del concurso "Premio Revista Chilena de Derecho", se decidió que estuviera dedicado a fomentar las áreas de Derecho Penal, Derecho Comercial y Análisis Económico del Derecho y Derecho Internacional.

El jurado que se nominó para la adjudicación de este premio estuvo conformado por los profesores UC Hernán Salinas (Derecho Internacional), Raúl Novoa (Derecho Comercial) y Alex van Weezel (Derecho Penal), todos ellos prestigiosos académicos de nuestra casa de estudios, a quienes manifiesto nuestro reconocimiento por su concienzuda y valiosa labor.

Desde el 1 de mayo y hasta el 30 de junio del presente año se extendió el plazo para presentar contribuciones para participar en el concurso, recibiendo una cantidad importante de artículos en cada una de las materias objeto del premio, debiendo hacer presente que en las bases del concurso se estableció que los postulantes no podían ser personas que se desempeñaran en el escalafón académico de nuestra universidad, ni tampoco que tuvieran con ella vínculos contractuales. 
A partir de los primeros días de julio y hasta fines de octubre se realizó el análisis y deliberación de los jueces respecto a los diversos trabajos presentados, y finalmente el 2 de noviembre se hicieron públicos los nombres de las personas ganadoras del concurso. En el área de Derecho Internacional fue premiada doña Ana María Moure; en Derecho Penal, don Fernando Fernández en Derecho Comercial y, finalmente, don Francisco Estrada en el área de Derecho Penal. Sus trabajos contaron con una evaluación formal, en los términos en que los árbitros de nuestra Revista revisan y califican los artículos científicos que en ella se publican, y sin perjuicio del reconocimiento que estos autores recibirán en una ceremonia oficial de nuestra Facultad, tenemos el agrado de incluir sus trabajos en el presente número de la Revista, destacando su originalidad y calidad.

Creemos que esta actividad es un modo muy adecuado de finalizar nuestras actividades del año 2011 y, al mismo tiempo, nos deja extremadamente motivados para iniciar las labores del año 2012, en el convencimiento que nuestra publicación constituye un elemento eficiente para incentivar y difundir la producción jurídica de nuestros autores y también de quienes nos envían sus trabajos desde el extranjero, y en que hemos sido cada vez más capaces de combinar la investigación y reflexión jurídicas con la experiencia material del Derecho aplicado, manteniendo la calidad y el interés de los materiales que damos a conocer a ustedes.

Como siempre, hago llegar mi agradecimiento y aprecio al equipo de la Revista Chilena de Derecho, que, con un trabajo arduo y responsable, hace posible cada una de las ediciones; a los autores y árbitros, por enriquecer y dar forma a nuestros proyectos; a las autoridades de la Facultad de Derecho, por su confianza y apoyo; a CONICYT y a la Pontificia Universidad Católica de Chile, por su importante aporte en fondos concursables para la Revista y, sobre todo, a nuestros lectores, a quienes se dirige y dedica la totalidad de nuestro trabajo.

Esperamos para todos ustedes una hermosa Navidad junto a sus familias y un nuevo año de grandes desafíos y de mucha fuerza, ánimo y esperanza para realizarlos.

Ángela Vivanco Martínez

Directora

Revista Chilena de Derecho 